\title{
Lipase-catalyzed regioselective synthesis of palmitolyglucose ester in ionic liquids*
}

\author{
Jintian Liang ${ }^{1}$, Wentian Zeng ${ }^{2}$, Pingjia Yao ${ }^{1 \#}$, Yuanan Wei ${ }^{1}$ \\ ${ }^{1}$ College of Life Science \& Technology, Guangxi University, Nanning, China \\ ${ }^{2}$ Guangzhou Institutes of Biomedicine and Health, Chinese Academy of Sciences, Guangzhou, China \\ Email: " pjyaogxu@126.cn
}

Received 12 February 2012; revised 2 May 2012; accepted 11 May 2012

\begin{abstract}
Candida antarctica lipase B (CAL-B) was used as a catalyst in the synthesis of palmitolyglucose ester in the ionic liquids, 1-butyl-3-methylimidazolium trifluoromethanesulfonate ([Bmim][TfO]), with glucose as a substrates and palmitic acid vinyl ester as the acyl donor. The effect of substrate ratio, lipase content, and temperature on the activity and stability of lipase was studied. The reaction conditions in [Bmim][TfO] resulting in the highest yield of the sugar ester were a temperature of $50^{\circ} \mathrm{C}$, enzyme concentration of $50 \mathrm{mg} /$ $\mathrm{mL}$, and a molar ratio of glucose/vinyl palmitate of 1:3. The major reaction product was purified and characterized by FT-IR, HPLC, MS and NMR, as being 6-O-palmitolyglucose ester. The advantages of ionic liquid vs. organic solvent were noted.
\end{abstract}

Keywords: Ionic Liquids; 6-O-Palmitolyglucose Ester; Lipase; Palmitic Acid Vinyl Ester; Glucose

\section{INTRODUCTION}

Fatty acid sugar esters have been widely used as sweeteners and non-ionic surfactants in pharmaceuticals, cosmetics, and food industries because they are biodegradable, non-toxic, and non-irritaing [1,2]. Currently, chemical synthesis is the major industrial method for sugar ester production. Existing chemical approaches have some obvious drawbacks, such as the low or non-selectivity for the site of estification, the requirement for protection and de-protection steps, and product purification difficulties. Since the discovery of lipase-catalyzed sugar esterification in organic solvents by the A. M. Klibanov [3] group in 1980's, the bio-catalytic synthesis of sugar esters has been studied extensively. This method of synthesis has the advantage of producing regio- and stereo-specific products under mild reaction condition [4-6]. However, the

\footnotetext{
*This research was supported by Guangxi Natural Science Foundation (No. 0991004)

${ }^{\#}$ Corresponding author.
}

organic solvents used in the enzymatic synthesis (e.g. pyridine) are toxic, volatile, and non-reusable. Moreover, most enzymes are quickly inactivated in the organic solvents [7]. To overcome these limitations, researchers have been seeking a reaction medium that can dissolve both polar-sugars and non-polar fatty acids, while at the mean time leaving the catalytic activity of the enzyme intact $[8,9]$.

During the past decade, ionic liquids (ILs) have been found to be suitable (even improved) replacements for the organic solvents in many reactions, ILs consist of anions and cations that have liquid properties at room temperature [10]. Compared to organic solvents, ionic liquids are relatively non-toxic, and do a better job of maintaining the enzyme activity and good substrate solubility [11-14]. Today, Ils have becomes a more attractive possibility as a reaction medium for used in selective acylation of carbohydrates.

The choice of solvent for the esterifications of glucose is very difficult, because one reactant is polar (glucose), the other is non-polar (fatty acid vinyl ester), and the product (glucose ester) is amphiphilic. Most ILs possess both a hydrophilic ionic head and a hydrophobic organic chain, comprising one category of surfactants. Therefore, ILs may be good solvents for the esterifications of glucose. The lipase-catalyzed transesterification of glucose with palmitic acid vinyl ester was performed in ILs. Although [Emim] [MS] is the most suitable ILs to dissolve glucose, no enzymatic reaction could be detected with this ILs. The acidic condition of this ILs may inactivate the enzyme. Only ILs containing the dicyanamide ([dca]) anion have been reported to be good solvents for sugar dissolution and enzyme reaction, but Candida antarctica lipase B(CAL-B) irreversibly deactivated in $[\mathrm{Bmim}][\mathrm{dca}]$ after reaction [15]. Therefore, a major problem in synthesizing sugar esters by using enzymes in non-aqueous media is the selection of an appropriate solvent to dissolve sugars.

In an effort to dissolve high concentrations of glucose and perform an enzyme reaction, $[\mathrm{Bmim}][\mathrm{TfO}],[\mathrm{Bmim}]$ $\left[\mathrm{BF}_{4}\right]$ and $[\mathrm{Bmim}]\left[\mathrm{PF}_{6}\right]$ was used as a reaction media for 
lipasecatalyzed transesterification. The [Bmim][TfO] has special properties: [Bmim][TfO] is fully miscible with water $\left(\mathrm{dH}^{1 / 4} / 47.8\right)$ but the Hildebrand solubility parameter of this ILs $\left(\mathrm{dH}^{1 / 425.4)}\right.$ is similar to that of [Omim][Tf2N] $\left(\mathrm{dH}^{1} / 425.0\right)$, which is known as a very hydrophobic and water immiscible ILs [16]. The Hildebrand solubility parameter has been widely used for predicting the solubilities of various chemicals in organic solvents. The maximum solubility is observed when the Hildebrand solubility parameters of the solute and solvent are identical. This implies that [Bmim][TfO] can dissolve not only hydrophilic substrates but also hydrophobic organic compounds. In addition, [Bmim][TfO] was reported to be a good reaction media for lipase-catalyzed reactions [17]. The transesterification of glucose could be performed in [Bmim][TfO] with high conversion.

In this paper, Candida antarctica lipase B (CAL-B) was used as the catalyst for the synthesis of palmitolyglucose ester in ILs, using glucose and palmitic acid vinyl ester as the substrates. The effects of substrate ratio, lipase content, and temperature on reaction yield were studied. The purified product was characterized by FT-IR, HPLC, MS and NMR. The results demonstrated that IL can be used as a "greener" solvent for sugar esterification, and illustrate the advantages of IL vs. organic for the specific lipase used for sugar ester synthesis.

\section{MATERIALS AND METHODS}

\subsection{Materials}

Candida antarctica lipase B(CAL-B), Thermomyces lanuginosus lipase and Mucor miehei lipase were purchased from Sigma. TOKYO Chemical Industry Co. Ltd. was the source of palmitic acid vinyl ester (99\%). 1-butyl-3-methylimidazolium trifluoromethanesulfonate ([Bmim][TfO]) was purchased from Shanghai Cheng Jie Chemical Co. LTD, China, while the Silica gel $\mathrm{G}$ and $\mathrm{H}$ were obtained from Qingdao Haiyang Chemical Co., Ltd. Tetrahydrofuran, chloroform, and methanol were all of analytical grade from commercial sources.

\subsection{Enzymatic Reactions in Ionic Liquid [Bmim][TfO]}

Glucose (0.2 g, $1.1 \mathrm{mmol})$ and vinyl palmitate $(0.94 \mathrm{~g}, 3.3$ mmol) were added to $5 \mathrm{~mL}$ [Bmim][TfO] in a $50 \mathrm{ml}$ beaker. The mixture was agitated at $40^{\circ} \mathrm{C}$, using a temperaturecontrolled incubation shaker (HWY211, Shanghai Zhi Cheng Co. LTD, China) at $200 \mathrm{r} / \mathrm{min}$ for $12 \mathrm{~h}$. The reactions were initiated by adding $0.25 \mathrm{~g}$ of lipase into the mixture. After $36 \mathrm{~h}$, the amounts of glucose and glucose esters in the reacting mixture were analyzed by Thin-layer Chromatography (TLC) and HPLC method. At the end of the reaction $36 \mathrm{~h}$, tetrahydrofuran (THF) was added to the reaction mixture, and filtered to recover the enzyme, and then the THF was removed by vacuum evaporation. Follow by adding deionized water $(1 \mathrm{~mL})$ to the system, and filtered the suspension and obtained the product as white solid, Filtrate including ionic liquids and palmitic acid vinyl ester, can be reused. The product was load onto a silica gel column and eluted with chloroform and methanol $(8: 1, \mathrm{v} / \mathrm{v})$. The purified sample was lyophilizaed and subjected to further analysis and characterization.

\subsection{Methods of Instrumental Analysis}

The product was analyzed by both TLC and HPLC methods. In TLC analysis, silica gel $\mathrm{G}$ recoated thin-layer chromatography plates (Qingdao fine chemical factory, China) was used, Chloroform/methanol (12/1, each by volume) was used as the developing system. TLC bands were visualized by spraying with reagent $(10 \%$ sulfuric acid aqueous solution) and dried at $105^{\circ} \mathrm{C}$.

The HPLC analysis was performed using a HPLC system (Waters $600 \mathrm{E}$, Waters, USA) equipped with a Diamonsil C18 column, a mobile phase consisting of methanol: water $(90: 10, \mathrm{v} / \mathrm{v})$ at a flow rate of $1 \mathrm{ml} / \mathrm{min}$. the injection volume was $10 \mu \mathrm{L}$ The eluant was analyzed with a light scattering detector (Alltech ELSD 2000) at $100^{\circ} \mathrm{C}$.

The electrospray ionization mass spectrometry (ESI-MS) analysis was carried out on a Agilent 1100LC/MSD instrument (Agilent, Trap SL USA) with $\mathrm{N}_{2}$ gas flow-rate of $10 \mathrm{~L} / \mathrm{min}$, and at a temperature of $350^{\circ} \mathrm{C}$.

FTIR spectra were recorded on a Nicolet-470 spectrometer. The dry samples were powdered, mixed with $\mathrm{KBr}$ and pressed into pellets under reduced pressure. The FTIR spectra were obtained by recording 128 scans between 4000 and $400 \mathrm{~cm}^{-1}$ with a resolution of $4 \mathrm{~cm}^{-1}$.

${ }^{1} \mathrm{H}$ NMR, ${ }^{13} \mathrm{C}$ NMR, ${ }^{1} \mathrm{H}-{ }^{1} \mathrm{H}$ COSY and ${ }^{13} \mathrm{C}-{ }^{1} \mathrm{H}$ HSQC spectra of the product were recorded on a Bruker Avance 500 spectrometer, using samples dissolved in $\mathrm{CD}_{3} \mathrm{OD}$ or DMSO-d6/TMS.

\section{RESULTS}

\subsection{The Solubility of Glucose in Different Ionic Liquids}

The solubilities of glucose in the various ILs at $25,40^{\circ} \mathrm{C}$, and Supersaturated Sugar Solution $\left(40^{\circ} \mathrm{C}\right)$ are shown in Table 1. ILs containing [dca $]^{-}$have been reported to have the greatest capacity to dissolve glucose, although the stability of lipase was too low in these ILs. The solubilities of glucose in ILs containing $\left[\mathrm{TfO}^{-},\left[\mathrm{BF}_{4}\right]^{-}\right.$and $\left[\mathrm{BF}_{6}\right]^{-}$were greatly influenced by temperature. The solubility of glucose in these ILs increased by a factor of 2 3 when the temperature was increased from $25^{\circ} \mathrm{C}$ to $40^{\circ} \mathrm{C}$, increased by a factor of $4-6$ when the solution was supersaturated at $40^{\circ} \mathrm{C}$. The solubility of glucose in [Bmim] 
[TfO] at supersaturated was the maximum $\left(40^{\circ} \mathrm{C}\right)$, therefore, the $[\mathrm{Bmim}][\mathrm{TfO}]$ was selected as a media for the transesterification reaction.

\subsection{Different Lipase Activities in Ionic Liquid}

Three enzymes were tested in our reaction system, using $[\mathrm{Bmim}][\mathrm{TfO}]$ as the reaction media. Figure 1 showed the final yield of the sugar ester with each of the enzymes. It is clear that CAL-B gave the highest yield (31.6\%), with Thermomyces lanuginosus lipase and Mucor miehei lipase yielding significantly less $(15.5 \%$ and $6.2 \%$, respectively). Therefore, the CAL-B lipase was used in the subsequent reactions.

\subsection{Optimization of Reaction Conditions}

The effects of substrate ratio, lipase content, and temperature on the activity and stability of CAL-B lipase were studied.

Figure 2 shows the effect of temperature on the reactions yield, showing that the yield of glucose palmitate was highest when the temperature was at $40^{\circ} \mathrm{C}$. These data suggest that the enzyme loses its activity at higher temperatures. Therefore, $40^{\circ} \mathrm{C}$ was taken as the optimum temperature for this CAL-B reaction system.

Table 1. Solubility and supersaturated concentration of glucose in ionic liquids.

\begin{tabular}{cccc}
\hline Solvent & $25^{\circ} \mathrm{C}$ & $40^{\circ} \mathrm{C}$ & $\begin{array}{c}\text { Supersaturated Sugar Solution } \\
\left(40^{\circ} \mathrm{C}\right)^{\mathrm{a}}\end{array}$ \\
\hline$[\mathrm{Bmim}][\mathrm{dca}]$ & 145 & - & \\
{$[\mathrm{Bmim}][\mathrm{TfO}]$} & 4.8 & 14.2 & 25.2 \\
{$[\mathrm{Bmim}]\left[\mathrm{BF}_{4}\right]$} & 0.9 & 2.7 & 5.1 \\
{$[\mathrm{Bmim}]\left[\mathrm{PF}_{6}\right]$} & $<0.5$ & - & 2.2
\end{tabular}

${ }^{a}$ Slowly cooled from $60^{\circ} \mathrm{C}$ to $40^{\circ} \mathrm{C}$. The supernatant was then carefully obtained after centrifugation.

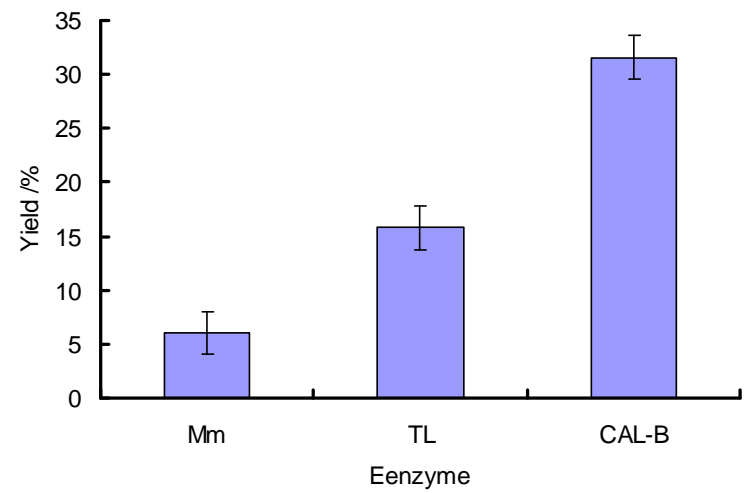

Mm: Mucor miehei; TL: Thermomyces lanuginosus; CAL-B: Candida antarctica lipase B.

Figure 1. Effect of enzymes on the esterification reaction of sugar.
Figure 3 shows the effect of the molar ratio of substrates (vinyl palmitate to glucose) on the yield of sugar ester in the presence of CAL-B at $40^{\circ} \mathrm{C}$. The highest yield was obtained when the molar ratio of vinyl palmitate to glucose was 1:3. At higher molar ratios the yield decreased. This could be due to the negative affect of excessive amount of palmitic acid vinyl ester on the catalytic efficiency, and decreased the reaction yield.

Figure 4 shows the effect of CAL-B enzyme concentration on the yield of sugar ester when the molar ratio of vinyl palmitate to glucose was fixed at 1:3 and the temperture was maintained at $40^{\circ} \mathrm{C}$. When enzyme concentration was $50 \mathrm{mg} / \mathrm{mL}$, the yield reached a maximum that plateaued at higher concentrations.

Candida antarctica lipase B (CAL-B) was used as the catalyst for the synthesis of palmitolyglucose ester in [Bmim][TfO], using glucose and palmitic acid vinyl ester as the substrates, the optimum reaction conditions were a temperature of $50^{\circ} \mathrm{C}$, enzyme concentration of $50 \mathrm{mg} / \mathrm{mL}$, and a molar ratio of glucose/vinyl palmitate of 1:3. Under these reaction conditions, the highest yield $(\%)$ of the reaction products was $31.8 \pm 1.2, \mathrm{n}=5$.

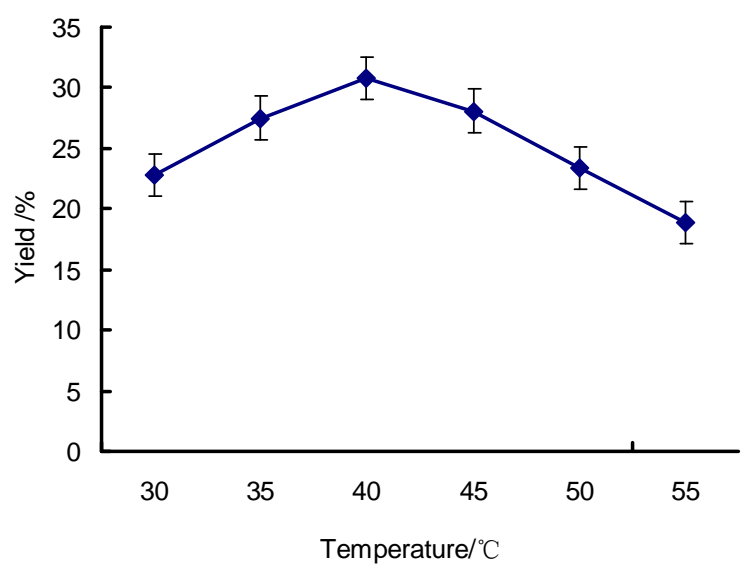

Figure 2. Effect of temperature on the reaction of sugar ester.

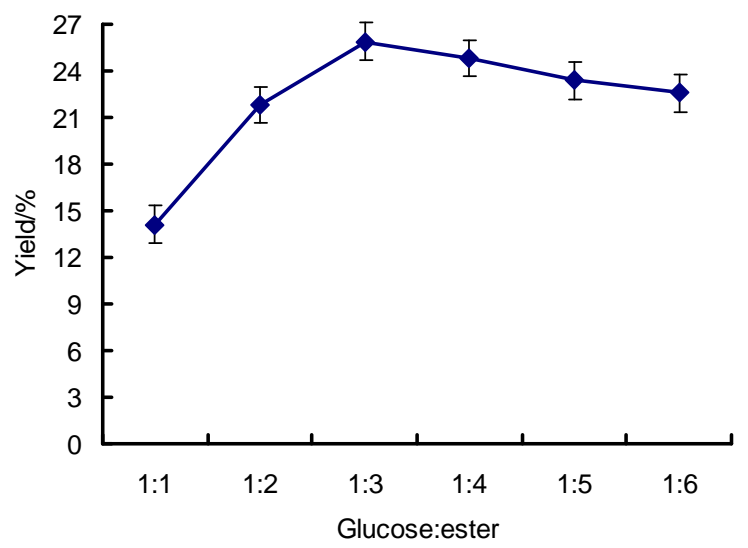

Figure 3. Effect of molar ratio of vinyl palmitate to glucose on the reaction of sugar ester. 


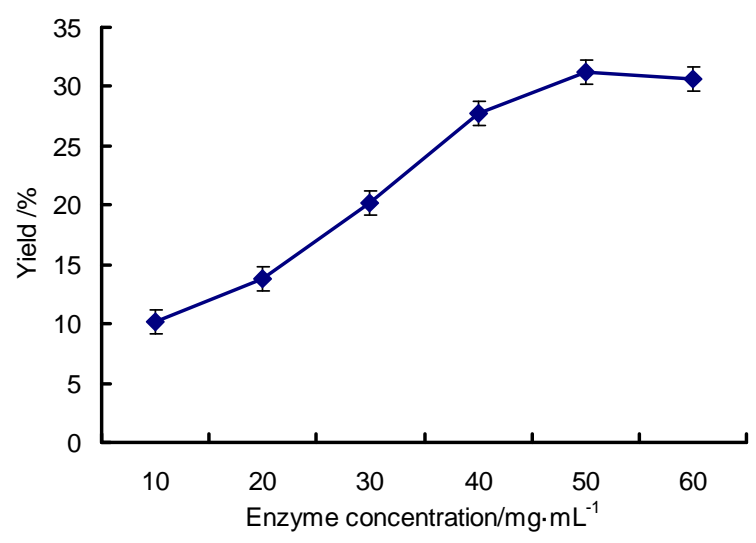

Figure 4. Effect of enzyme concentration on the reaction of sugar ester.

\subsection{Characterization of Reaction Product}

The FT-IR spectra of glucose, palmitic acid vinyl ester and the reaction product are shown in Figure 5, The vibrations absorbance of-OH $\left(-3412 \mathrm{~cm}^{-1}\right)$, C-H $(2914$ $\left.\mathrm{cm}^{-1}, 2855 \mathrm{~cm}^{-1}\right), \mathrm{C}=\mathrm{O}\left(1727 \mathrm{~cm}^{-1}\right), \mathrm{C}-\mathrm{O}-\mathrm{C}\left(1174 \mathrm{~cm}^{-1}\right)$ in the product indicate that transesterification between glucose and palmitic acid vinyl ester has occurred.

HPLC analysis of the purified reaction product (Figure 6) shows only a single peak, and its ESI-MS spectrum (Figure 7) shows the principal signal at $443 \mathrm{~m} / \mathrm{z}$ $[\mathrm{M}+\mathrm{Na}]^{+}$. This is consistent with the molecular weight of palmitotyl glucose monoester (420).

The $1 \mathrm{H}$ and C13 NMR signals of the purified product were assigned by comparison of the spectra of the product

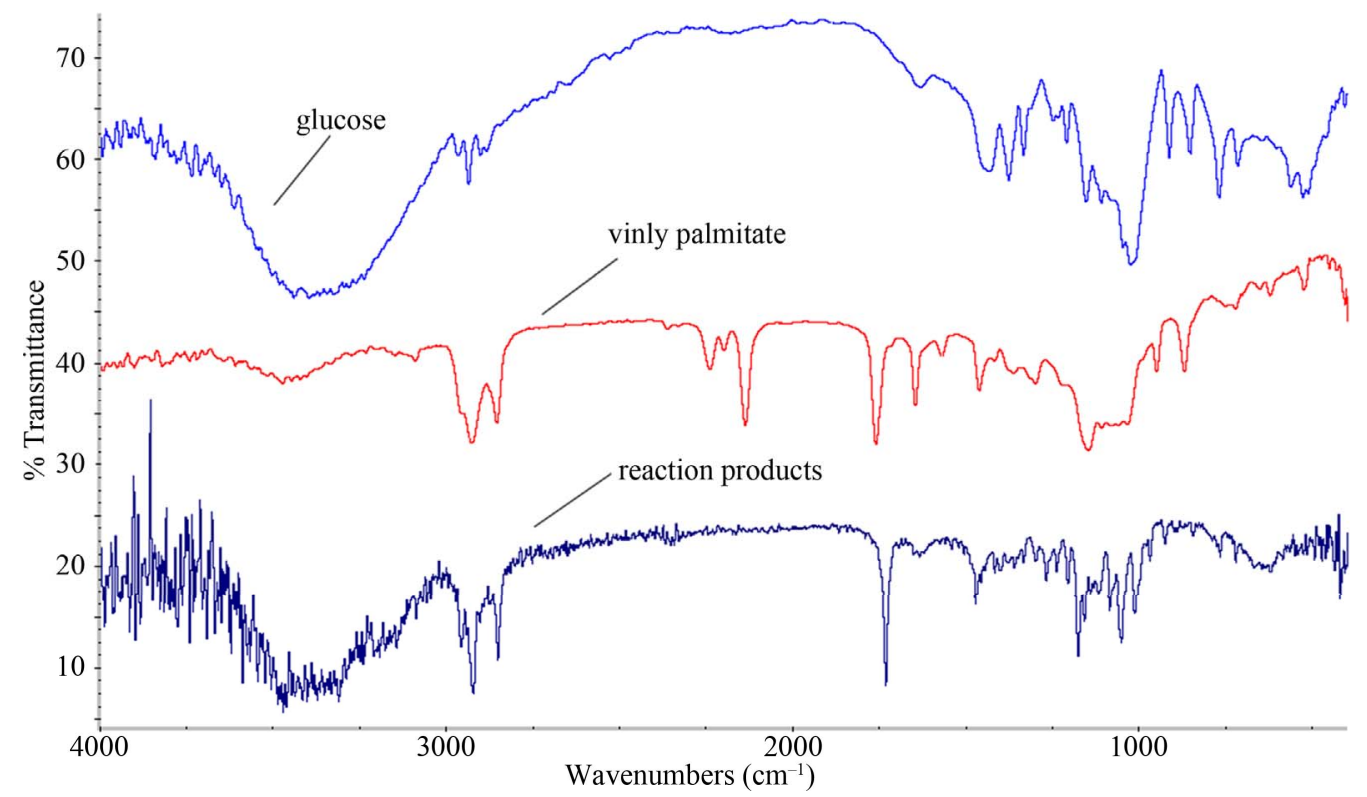

Figure 5. The FT-IR spectrum of glucose, vinly palmitate and reaction products.

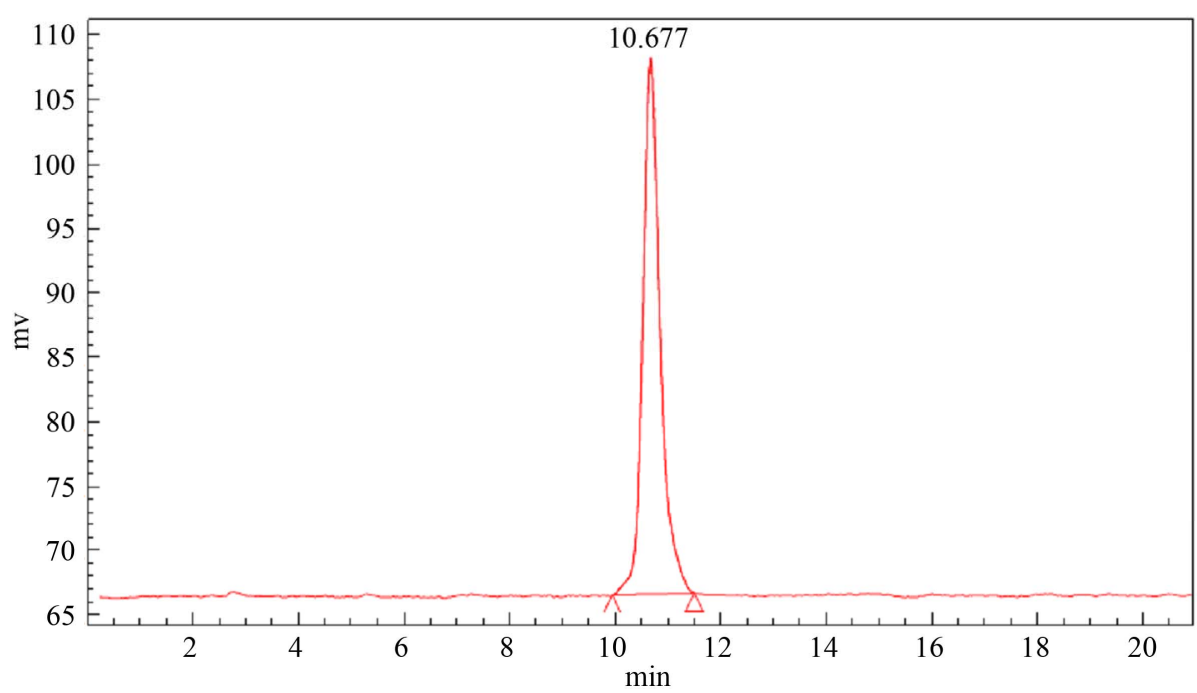

Figure 6. HPLC chromatogram of reaction products. 
with the spectra of reactants (glucose and palmitic acid vinyl ester) and by two-dimensional spectra, specifically ${ }^{1} \mathrm{H}-{ }^{1} \mathrm{H}$ COSY and ${ }^{1} \mathrm{H}_{-}{ }^{13} \mathrm{C}$ HSQC. Table 2 gives the $1 \mathrm{H}$ and $13 \mathrm{C}$ chemical shifts of NMR signals in the product.

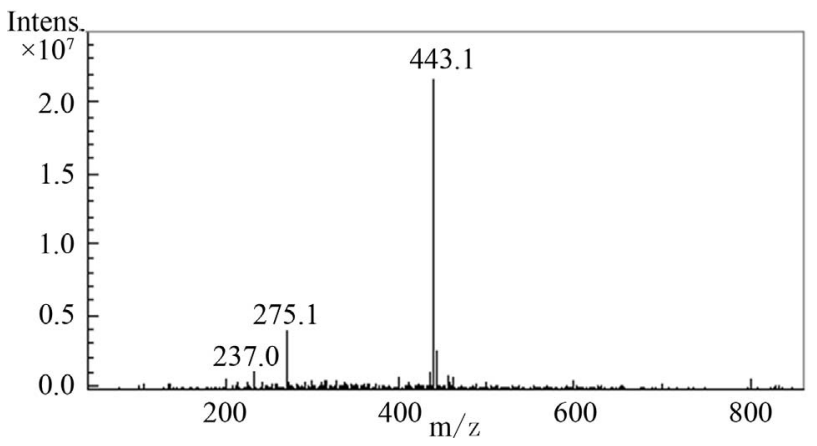

Figure 7. ESI-MS spectrum of reaction products.

Table 2. ${ }^{1} \mathrm{H}$ and ${ }^{13} \mathrm{C}-\mathrm{NMR}$ data of the reaction products in $\mathrm{CD}_{3} \mathrm{OD}$.

\begin{tabular}{ccc}
\hline & ${ }^{13} \mathrm{C} \mathrm{NMR} / \mathrm{ppm}$ & ${ }^{1} \mathrm{H}$ NMR $/ \mathrm{ppm}$ \\
\hline Glucosyl & & \\
1 & 93.02 & 4.88 \\
2 & 72.82 & 3.12 \\
3 & 74.07 & 3.02 \\
4 & 70.84 & 3.40 \\
5 & 69.80 & 3.75 \\
6 & 64.14 & $4.26(\alpha), 3.96(\beta)$ \\
$1^{\prime}\left(\right.$ Carbonyl-C) $^{\prime}$ & 175.17 & 2.26 \\
$3^{\prime}$ & 34.55 & 1.49 \\
$-\mathrm{CH}_{2}-\left(\mathrm{C}_{4}{ }^{\prime}-\mathrm{C}_{14}{ }^{\prime}\right)$ & 25.25 & $1.24(\mathrm{br} . \mathrm{m})$ \\
$15^{\prime}$ & $30.02,30.19,30.24$ & 0.86 \\
$16^{\prime}$ & 23.02 & 0.84 \\
\hline
\end{tabular}

Figure 8 shows the ${ }^{1} \mathrm{H}-{ }^{13} \mathrm{C}$ HSQC spectrum in the center, the proton spectrum in the top, and carbon spectrum in the left panel. The major proton-carbon cross-peaks were assigned and are labeled in the HSQC spectrum.

It is clear that the signal of carbon 6 (C-6) of glucose has shifted down field to $64.14 \mathrm{ppm}$, compared with the regular C-6 of glucose at $61.28 \mathrm{ppm}$, this indicate that the esterification has occurred on the hydroxyl group of carbon $6(6-\mathrm{OH})$ of glucose.

Taking all of these data into consideration, the reaction product was determined to be 6-O-palmitolyglucose ester, with the structure shown in Figure 9, where the numbers denote the NMR assignments in Table 2.

\section{DISCUSSION}

Enzyme activities of CAL-B in ILs (e.g. [BMIM] $\left[\mathrm{BF}_{4}\right]$ or $[\mathrm{BMIM}]\left[\mathrm{PF}_{6}\right]$, were reported controversially for transesterification [18]. In the current investigation, three commercial lipases were chosen for testing in an IL [Bmim][TfO]. The results show that CAL-B lipase had the highest yield and stability in this system. The glucose transesterification was shown to occur at the 6-OH of the sugar ring as illustrated in the Scheme 1.

The lipase-catalyzed reaction was monitored by TLC and HPLC methods, showing that CAL-B lipase had catalyzed a good region-selectivity esterification of glucose in this IL system. The 6-hydroxyl substitution of glucose monoester was the principal product, together with the advantage of easy remove and re-use of the ionic liquid, these really made the following separation and purification of the product to be much quicker and easier.

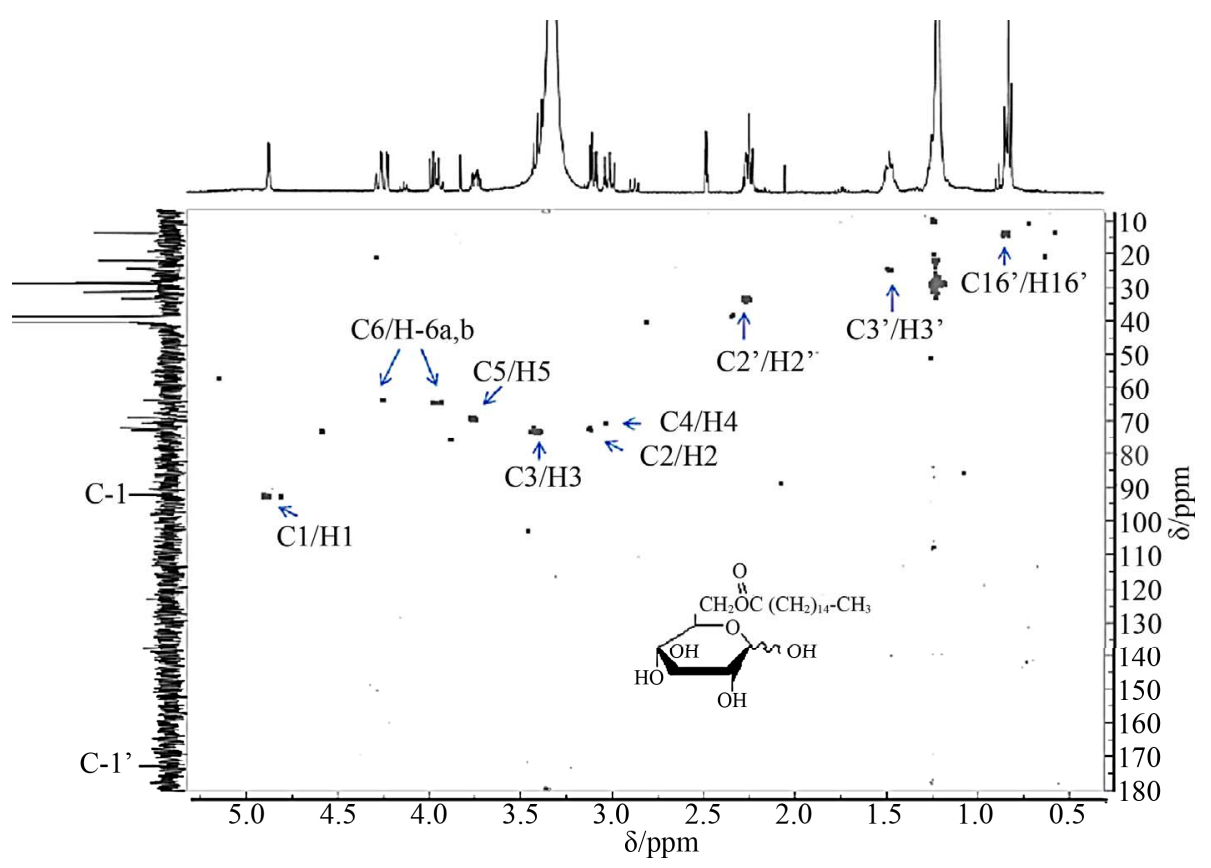

Figure 8. ${ }^{1} \mathrm{H}-{ }^{13} \mathrm{C}$ HSQC of the synthetic products in $\mathrm{CD}_{3} \mathrm{OD}$ and DMSO-d6. 


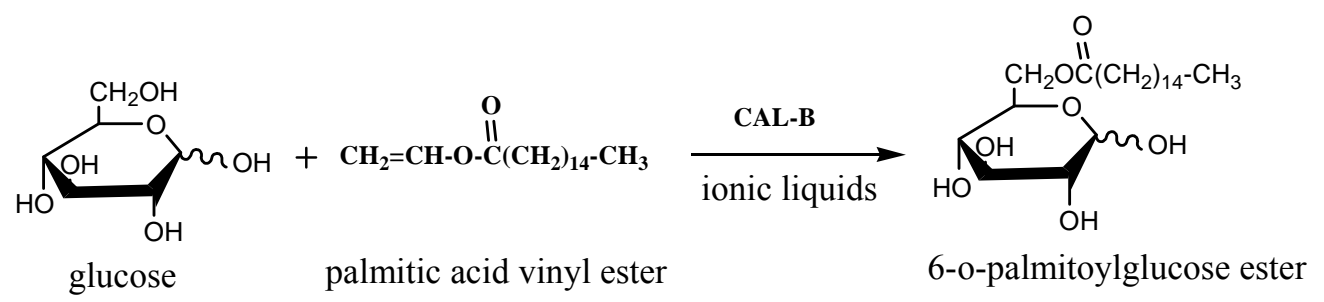

Scheme 1. The rection equatio of transesterification of glucose and palmitic acid vinyl ester.

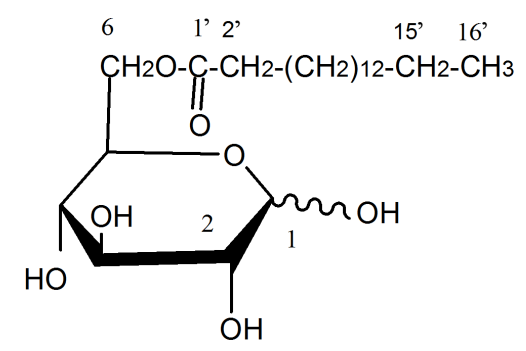

Figure 9. Structure of reaction products.

We have reported previously that in organic solvents, many lipase enzymes, including CAL-B, Novozym-435 and others, tend to selectively catalyze the O-6-glucose selected esterification [19]. For example,lipase was used as the catalyst for the esterification of 6-O-(10-undercylenoyl)-D-glucose in non-aqueous phase, using glucose and 10-Undecylenic acid as the substrates. When the reaction occurred in 2-methyl-2-butanol or butanone, the highest yield was obtained $30.55 \%$ and $26.33 \%$ respectively. However, in this study the highest yield of reaction products was obtained $31.8 \%$. Comparing those results with the current results, it is clear that CAL-B lipase in the IL has the same regional selectivity as it did in organic solvents.

Ionic liquids (ILs) are organic salts that completely constituted by the ions and liquid state at room temperature or near room temperature. Their non-volatile character and environmentally friendly make them attractive alternatives for volatile organic solvents. In chemical reaction, ILs exhibit excellent characteristics including the ability to dissolve polar and non-polar organic compounds. Therefore, ILs may be good solvents for the esterifications of glucose. Moreover, the IL seems to be more enzyme-compatible in that it allows more substrate (e.g., sugar) to access the active site of the enzyme. The IL has the added advantage of easy removal and re-use, thereby simplifying, facilitating, and "greening" the reaction.

In summary, this experiment illustrates that the ionic liquid is a preferred reaction medium for sugar esterification.

\section{CONCLUSION}

In this paper, Candida antarctica lipase B (CAL-B) was used as a catalyst in the synthesis of palmitolyglucose ester in the ionic liquids, 1-butyl-3-methylimidazolium trifluoromethanesulfonate ([Bmim][TfO], with glucose as a substrates and palmitic acid vinyl ester as the acyl donor. The effect of substrate ratio, lipase content, and temperature on the activity and stability of lipase was studied. The reaction conditions in [Bmim][TfO] resulting in the highest yield of the sugar ester were a temperature of $50^{\circ} \mathrm{C}$, enzyme concentration of $50 \mathrm{mg} / \mathrm{mL}$, and a molar ratio of glucose/vinyl palmitate of 1:3. The major reaction product was purified and characterized by FT-IR, HPLC, MS and NMR, as being 6-O-palmitolyglucose ester. The advantages of ionic liquid vs. organic solvent were noted.

\section{REFERENCES}

[1] Flores, M.V., Naraghi, K., Engasser, J.M. and Halling, P.J. (2002) Influence of glucose solubility and dissolution rate on the kinetics of lipase catalyzed synthesis of glucose laurate in 2-methyl 2-butanol. Biotechnology and Bioengineering, 78, 814-820. doi:10.1002/bit.10263

[2] Kennedy, J.F., Kumar, H., Panesar, P.S., Marwaha, S.S., Goyal, R., Parmar, A. and Kaur, S. (2006) Enzyme-catalyzed regioselective synthesis of sugar esters and related compounds. Journal of Chemical Technology \& Biotechnology, 81, 866-876. doi:10.1002/jctb.1473

[3] Liu, Q.B., Michiel, H., Janssen, A., Rantwijk, F.V. and Sheldon, R.A. (2005) Room-temperature ionic liquids that dissolve carbohydrates in high concentrations. Green Chemistry, 7, 39-42. doi:10.1039/b412848f

[4] Wei, Y.A., Zhang, Y. and Yao, P.J. (2009) Enzymecatalyzed regioselective synthesis of sucrose vinyl adipoyl ester by an immobilized proleather. Journal of Guangxi Normal University: Natural Science Edition, 34, 484-490.

[5] Ganske, F. and Bornscheuerv, U.T. (2005) Optimization of lipase-catalyzed glucose fatty acid ester synthesis in a two-phase system containing ionic liquids and $\mathrm{t}-\mathrm{BuOH}$. Journal of Molecular Catalysis B: Enzymatic, 36, 40-42. doi:10.1016/j.molcatb.2005.08.004

[6] Riva, S., Chopineau, J., Kieboom, A.P.G. and Klibanov, A.M. (1988) Protease-catalyzed regioselective esterification of sugars and related compounds in anhydrous dimethylformamide. Journal of the American Chemical Society, 110, 584-589. doi:10.1021/ja00210a045

[7] Soedjak, H.S. and Spradlin, J.E. (1994) Enzymatic transesterification of sugars in anhydrous pyridine. Biocatalysis and Biotransformation, 11, 241-248. 


\section{doi:10.3109/10242429408998144}

[8] Plou, F.J., Cruces, M.A., Bernable, M., Martin-Loma, M., Parra, J.L. and Ballesteros, A. (1995) Enzymatic synthesis of partially acylated sucrosesa. Annals of the New York Academy of Sciences, 750, 332-337. doi:10.1111/j.1749-6632.1995.tb19976.x

[9] Rich, J.O., Bedell, B.A. and Dordick, J.S. (1995) Controlling enzyme-catalyzed regioselectivity in sugar ester synthesis. Biotechnology and Bioengineering, 45, 426434. doi:10.1002/bit.260450507

[10] Yang, Z. and Pan, W.B. (2005) Ionic liquids: Green solvents for nonaqueous biocatalysis. Enzyme and Microbial Technology, 37, 19-28. doi:10.1016/j.enzmictec.2005.02.014

[11] Kimizuka, N. and Nakashima, T. (2001) Spontaneous self-assembly of glycolipid bilayer membranes in sugarphilic ionic liquids and formation of ionogels. Langmuir, 17, 6759-6761. doi:10.1021/la015523e

[12] Swatloski, R.P., Spear, S.K., Holbrey, J.D. and Rogers, R.D. (2002) Dissolution of cellose with ionic liquids. Journal of the American Chemical Society, 124, 49744975. doi: $10.1021 / \mathrm{ja} 025790 \mathrm{~m}$

[13] MacFarlane, D.R., Golding, J., Forsyth, S., Forsyth, M. and Deacon, G.B. (2001) Low viscosity ionic liquids based on organic salts of the dicyanamide anion. Chemical Communications, 16, 1430-1431. doi:10.1039/b103064g

[14] Forsyth, S.A., MacFarlane, D.R., Thomson, R.J. and Itz- stein, M.V. (2002) Rapid, clean, and mild O-acetylation of alcohols and carbohydrates in an ionic liquid. Chemical Communications, 7, 714-715. doi:10.1039/b200306f

[15] Liu, Q.B., Janssen, M.H.A., Van Rantwijk, F. and Sheldon, R.A. (2005) Room-temperature ionic liquids that dissolve carbohydrates in high concentrations. Green $\mathrm{Ch}$ emistry, 7, 39-42. doi:10.1039/b412848f

[16] Lee, S.H. and Lee, S.B. (2005) The Hildebrand solubility parameters, cohesive energy densities and internal energies of 1-alkyl-3-methylimidazoliumbased room temperature ionic liquids. Chemical Communications, 27, 34693471. doi:10.1039/b503740a

[17] Itoh, T., Akasaki, E., Kudo, K. and Shirakami, S. (2001) Lipase-catalyzed enantioselective acylation in the ionic liquid solvent system: Reaction of enzyme anchored to the solvent. Chemistry Letters, 3, 262-263. doi:10.1246/cl.2001.262

[18] Forsyth, S.A. and MacFarlane, D.R. (2003) 1-Alkyl-3methylbenzotriazolium salts: Ionic solvents and electrolytes. Journal of Materials Chemistry, 13, 2451-2456. doi:10.1039/b307931g

[19] Wang, Y.Z., Li, Q.L., Yue, W., Yao, P.J. and Wei, Y.A. (2012) 6-O-(10-undecylenoyl)-D-glucose: Controlled enzymatic synthesis and structure elucidation by ${ }^{1} \mathrm{H}$ and ${ }^{13} \mathrm{C}$ NMR. Advanced Materials Research, 396-398, 13181324. doi:10.4028/www.scientific.net/AMR.396-398.1318 